\title{
PENGEMBANGAN BUDIDAYA LEBAH MADU TRIGONA SPP RAMAH LINGKUNGAN DI DESA ANTAPAN KECAMATAN BATURITI KABUPATEN TABANAN
}

\author{
M. Dewantari ${ }^{1}$ dan I.G. Suranjaya ${ }^{2}$
}

\begin{abstract}
ABSTRAK
Kegiatan pengabdian kepada masyarakat melalui program Kuliah Kerja Nyata Pembelajaran Pemberdayaan Masyarakat yang dilakukan di Desa Antapan, Kecamatan Baturiti , Kabupaten Tabanan bertujuan meningkatkan pendapatan masyarakat sasaran melalui peningkatan produktivitas dan pemasaran madunya hasil dari pengembangan lebah madu lokalnya yang ramah lingkungan. Metode kegiatan yang diterapkan dalam pemberdayaan masyarakat pada program Kuliah Kerja Nyata Pembelajaran Pemberdayaan Masyarakat adalah sebagai berikut: (1)..Koordinasi dan komunikasi dengan mitra sasaran untuk merumuskan program mulai dari perencanaan, operasional dan evaluasi, (2).Penyuluhan teknik tata cara budidaya lebah madu lokal serta penyuluhan produksi madu yang higienis. Disamping itu juga dilaksanakan studi banding ke kelompok lebah madu yang sudah maju di Jembrana, . (3)Pengenalan rancang bangun stup (kotak lebah) sistim kotakyang modern serta penyerahan bantuan 40 stup ke kelompok lebah madu yang sudah ada lebahnya, bersamaan itu juga dilakukan demo cara memperbanyak koloni. Hasil dari kegiatan ini menunjukkan bahwa semua kegiatan yang dilakukan berjalan dengan lancar serta mendapat respon yang positip dari Kepala Desa beserta jajaran aparat desanya serta kelompok lebah madu.
\end{abstract}

Kata kunci : lebah trigona, pengembangan, desa antapan.

\begin{abstract}
Community service activities through the Community Empowerment Learning Learning Real Work program conducted in Antapan Village, Baturiti Subdistrict, Tabanan Regency aim to increase target community income through increasing productivity and marketing of honey resulting from the development of environmentally friendly local honey bees. The methods of activities applied in community empowerment in the Community Empowerment Learning Learning Real Lecture program are as follows (1) .. Coordination and communication with target partners to formulate programs starting from planning, operations and evaluation (2). Extension of honey beeskeeping techniques. local and hygienic honey production counseling. Besides that, a comparative study was also carried out to the advanced honeybee group in Jembrana. (3) Introduction of the modern bee-box design (bee box) and the delivery of 40 bee aid to the honey bee group which has bees, at the same time a demonstration on how to multiply the colony is carried out. The results of this activity indicate that all activities carried out went smoothly and received positive responses from the farmers.
\end{abstract}

Keywords: trigona bees, development, productivity, antapan viilage.

\section{PENDAHULUAN}

\footnotetext{
${ }^{1}$ Fakultas Peternakan Universitas Udayana, e-mail : dewantari@unud.ac.id .

${ }^{2}$ Fakultas Peternakan Universitas Udayana,.
} 


\section{Dewantari dan I.G. Suranjaya}

Desa Antapan Kecamatan Baturiti Kabupaten Tabanan adalah desa dengan cakupan wilayahnya berupa lahan pertanian, perkebunan dan kawasan hutan rakyat yang masih cukup luas. Desa ini dipilih sebagai lokasi pelaksanaan program pemberdayaan masyarakat KKN-PPM Pengembangan Budidaya Lebah madu lokal Trigona sp ramah lingkungan. Kawasan ini sangat cocok sebagai lokasi pengembangan budidaya lebah Trigona sp karena berada di daerah pinggiran hutan dengan vegetasi tanaman bunga, buah dan kayu yang berlimpah sebagai sumber pakan lebah. Adalah Kelompok Peternak lebah madu "Manggar Sari", yang beranggotakan 20 orang petani di desa itu telah mulai membudidayakan lebah madu lokal Trigona sp untuk dapat menunjang pendapatan keluarga.

Namun permasalahan utama yang dihadapi oleh kelompok peternak lebah di desa ini adalah manajemen kelembagaan kelompok yang masih lemah terutama dalam budidaya lebah Trigona sp, perilaku petani kelompok belum memiliki kepedulian terhadap pemeliharaan tanaman pakan lebah dan cendrung membiarkan tanaman begitu saja tanpa melakukan pemeliharaan, penggunaan stup (kotak lebah) belum sesuai anjuran, penanggulangan penyakit dan teknik panen yang juga belum baik. Terbatasnya pengetahuan dan pemahaman kelompok tentang budidaya lebah Trigona Spp. dan pengelolaan panen madu merupakan faktor yang dapat menurunkan produktivitas usaha budidaya lebah itu. Madu sesungguhnya mampu menjadi komoditi unggulan dari desa Antapan, namun bila pengetahuan serta pemahaman kelompok peternak masih rendah, tentu saja dapat menjadi halangan bagi kemajuan produktivitas dan kualitas dari madu yang dihasilkan. Dari permasalahan yang terdapat di kelompok tersebut adalah berdampak kepada produksi madu yang selama ini dihasilkan baik dari segi kualitas maupun dari segi kuantitasnya belum optimal sehingga belum mampu memberi kontribusi optimal terhadap pendapatan masyarakat.

Lebah trigona adalah serangga kecil berwarna hitam, dengan panjang tubuh antara 3-4 mm, serta rentang sayap $\square 8 \mathrm{~mm}$ (Surata, 2017). Lebah pekerja memiliki kepala besar dan rahang panjang. Sedang lebah ratu berukuran 3-4 kali ukuran lebah pekerja, perut besar mirip laron, berwarna kecoklatan dan mempunyai sayap pendek. Lebah ini tidak mempunyai sengat (stingless bee). Produksi dan perkembangan dari lebah Trigona sp ini sangat dipengaruhi oleh faktor lingkungan, meliputi suhu, kelembaban udara, curah hujan dan ketinggian tempat. Disamping itu ketersedian pakan sangat menentukan keberhasilan budidaya lebah trigona. Dalam upaya peningkatan produksi madu baik dari segi kualitas maupun kuantitas sangat berkaitan dengan temperatur udara, kebersihan dan keamanan stup, penggunaan stup yang modern, penerapan teknik budidaya lebah yang baik, serta pengendalian hama dan penyakit lebah. Dengan meningkatnya produksi madu, nanti pada akhirnya diharapkan dapat meningkatkan pendapatan petani kelompok lebah madu khususnya dan masyarakat desa Antapan umumnya. Dalam situasi seperti ini, budidaya lebah madu Trigona sp menjadi salah satu pilihan. Lebah kecil yang tidak memiliki sengat ini tidak hanya menghasilkan madu, tetapi juga propolis yang memiliki nilai ekonomi cukup tinggi.

Berdasarkan hal tersebut, maka untuk mengoptimalkan potensi yang dimiliki masyarakat desa Antapan, Kecamatan Baturiti, Kabupaten Tabanan dengan mengimplentasikan teknologi sebagai inovasi dalam pemberdayaan masyarakatnya maka melalui program KKN-PPM dengan kegiatan pengembangan lebah madu lokal Trigona sp yang ramah lingkungan ini dilakukan untuk dapat menunjang peningkatan pendapatan masyarakatnya.

\section{METODE PELAKSANAAN}

\subsection{Metode}

Metode yang diterapkan pada pemberdayaan kelompok mitra sasaran ini sebagai berikut: (1) Sosialisasi dan koordinasi dengan kelompok mitra sasaran, 2). Penyuluhan dan pelatihan singkat mengenai teknologi budidaya lebah Trigona spp., dan (3) Pendampingan secara berkala dan 
berkelanjutan kepada kelompok sasaran hingga ipteks yang dialihkan dapat dilaksanakan secara mandiri.

\subsection{Tahap kegiatan}

Pelaksananan kegiatan alihteknologi budidaya lebah madu lokal Trigona sp adalah sebagai berikut :

(1) Kordinasi dan komunikasi secara partisipasif dengan petani kelompok sasaran untuk merumuskan program mulai dari perencanaan, operasional dan evaluasi

(2) Penyuluhan dan pelatihan teknik budidaya lebah dan teknik panen madu yang higienis.

(3) Pelatihan manajemen administrasi pembukuan bagi staf pengurus kelompok ternak lebah.

(4) Pembuatan demoplot, rancang bangun stup sistem kotak dan pendampingan budidaya lebah madu Trigona sp.

(5) Studi banding / kunjungan ke kelompok peternak lebah madu "Usada" di desa Dlod Berawah Kecamatan Mendoyo Kabupaten Jembrana.

(6) Monitoring dan Evaluasi.

\section{HASIL DAN PEMBAHASAN}

Pelaksanaan kegiatan ini dilakukan pada kelompok peternak lebah madu "Manggar Sari" di desa Antapan, Kecamatan Baturiti-Kabupaten Tabanan dengan jumlah anggota sebanyak 20 orang petani. Kegiatan dilakukan selama 1 bulan mulai dari bulan Juli sampai Agustus 2018. Penyuluhan dan pelatihan singkat dilakukan selama 1 hari tentang ipteks yang didesiminasikan pada mitra sasaran yaitu teknologi budidaya lebah Trigona spp. dan teknik panen madu secara hegienis. Masyarakat mitra sasaran nampak sangat antusias dan tertarik dengan inovasi yang ditawarkan (Gambar 1).

Tabel 1. Tingkat Partisipasi Mitra Sasaran

\begin{tabular}{|c|c|c|c|}
\hline \multirow[b]{2}{*}{ No } & \multirow[b]{2}{*}{ Kegiatan } & \multicolumn{2}{|c|}{ Partisipasi } \\
\hline & & $\begin{array}{l}\text { Jumlah } \\
\text { (orang) }\end{array}$ & $\%$ \\
\hline 1 & $\begin{array}{l}\text { Penyuluhan singkat teknik budidaya lebah } \\
\text { dan produksi madu yg hiegenis } \\
\text { - Kehadiran } \\
\text { - Tertarik \& mengungkapkan masalah }\end{array}$ & $\begin{array}{l}20 \\
16\end{array}$ & $\begin{array}{c}100 \\
80\end{array}$ \\
\hline & $\begin{array}{l}\text { Pelatihan manajemen administrasi } \\
\text { - Pelatihan administrasi pembukuan } \\
\text { bagi staff pengurus kelompok }\end{array}$ & 6 & 100 \\
\hline 3 & $\begin{array}{l}\text { Demoplot Budidaya lebah Trigona sp } \\
\text { - Rancang bangun stup sistem kotak } \\
\text { - Teknologi pemindahan koloni dan ratu }\end{array}$ & $\begin{array}{l}16 \\
15\end{array}$ & $\begin{array}{l}80 \\
75\end{array}$ \\
\hline 4 & $\begin{array}{l}\text { Studi banding. } \\
\text { - Studi banding ke peternakan lebah } \\
\text { Trigona di Kab. Jembrana } \\
\text { - Diskusi dgn peternak vang lebih maju }\end{array}$ & 20 & 100 \\
\hline
\end{tabular}


Hal ini disebabkan karena melalui teknologi budidaya lebah Trigona spp ini disamping dapat dihasilkan madu "kele" yang sangat bermanfaat bagi kesehatan, budidaya lebah Trigona sp ini juga sangat menunjang rencana pengembangan wisata trekking (wisata alam) menyusuri hutan alam di desa Antapan karena lebah Trigona spp adalah tergolong jinak dan tidak menyengat sehingga tidak membahayakan para wisatawan. Pada penyuluhan itu dijelaskan bahwa lebah trigona adalah serangga jinak berwarna hitam dan berukuran kecil, dengan panjang tubuh antara 3$4 \mathrm{~mm}$, serta rentang sayap $8 \mathrm{~mm}$. Menurut Sihombing (2005) setiap koloni terdiri dari ratu, lebah pekerja dan lebah jantan. Lebah ratu merupakan satu-satunya lebah petelur seumur hidup dalam satu koloni. Lebah pekerja adalah lebah betina yang organ reproduksinya tidak berfungsi sempurna/ tidak subur. Lebah pekerja mengeluarkan lilin yang digunakan untuk membangun, membersihkan dan memelihara sarang, menjaga sarang, menyediakan makanan, terdiri dari madu dan tepung sari. Untuk kehidupan dan perkembangannya lebah trigona dipengaruhi oleh faktor lingkungan seperti suhu, curah hujan, ketinggian tempat dan ketersedian pakan. Kehadiran dan partisipasi anggota kelompok dari mitra sasaran pada beberapa tahapan kegiatan dapat dikatagorikan sangat baik. Tingkat kehadiran dan partisipasi mitra sasaran pada setiap tahapan kegiatan berkisar 75 - 100\% (Tabel 1). Kelompok mitra sasaran dapat merasakan bahwa inovasi pengembangan budidaya lebah trigona dirasakan sangat bermanfaat dan nantinya dapat menunjang ekonomi keluarga. Menurut Chambers (1987) bahwa masyarakat perdesaan lebih mudah menerima inovasi yang sederhana, mudah dipahami dan dapat dirasakan akan manfaatnya.

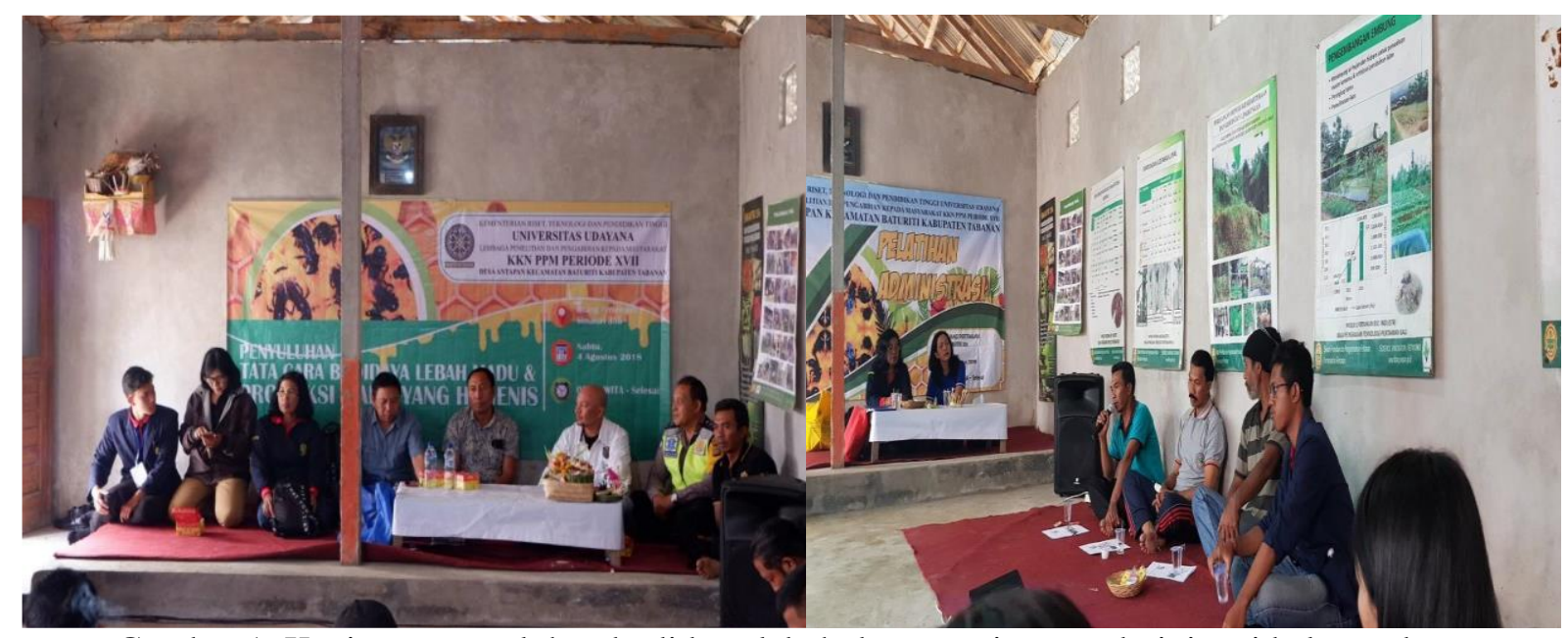

Gambar 1. Kegiatan penyuluhan budidaya lebah dan manajemen adminitrasi kelompok

Diberikan pula penyuluhan dan pelatihan tentang manejemen administrasi pembukuan dan pemasaran khusus kepada staf pengurus kelompok dalam upaya untuk penguatan aspek manajemen kelompok. Penguatan kelompok sangat penting dilakukan agar kelompok tetap dapat melakukan aktivitasnya dan juga untuk menunjang keberlanjutannya.

Pada kegiatan demoplot dilakukan pendampingan terhadap mitra sasaran pada teknik rancang bangun stup sistem kotak dan pemindahan koloni lebah. Rancang bangun stup lebah Trigona sp dibuat menggunakan kayu hutan yang berserat halus seperti albesia atau kayu pandan hutan dengan ukuran standard yang digunakan $40 \times 20 \times 15 \mathrm{~cm}$ dan $30 \times 15 \times 10 \mathrm{~cm}$ berbentuk kotak sehingga disebut stup sistem kotak. Stup lebah Trigona spp bisa digantung ataupun disusun pada rak dan diletakkan di tempat teduh, tidak kena hujan dan sinar matahari langsung. Pemeliharaan stup dilakukan secara rutin dan periodik, meliputi pembersihan dari sarang semut/ laba-laba, pengecekan kondisi stup agar tidak terkena air hujan. Stup juga harus dihindarkan dari hama pengganggu seperti cecak, tokek, larva kumbang, tawon kuning, ayam dan lain-lain. Sebanyak $80 \%$ dari total anggota kelompok atau sekitar 16 orang anggota kelompok mampu membuat rancang 
bangun stup sistem kotak dengan baik. Pada pelaksanaan program KKN-PPM ini juga diberikan bantuan sebanyak 40 buah stup yang sudah berisi lebah ratu kepada kelompok dan ditempatkan secara kolektif di salah satu lokasi anggota kelompok (Gambar 2).
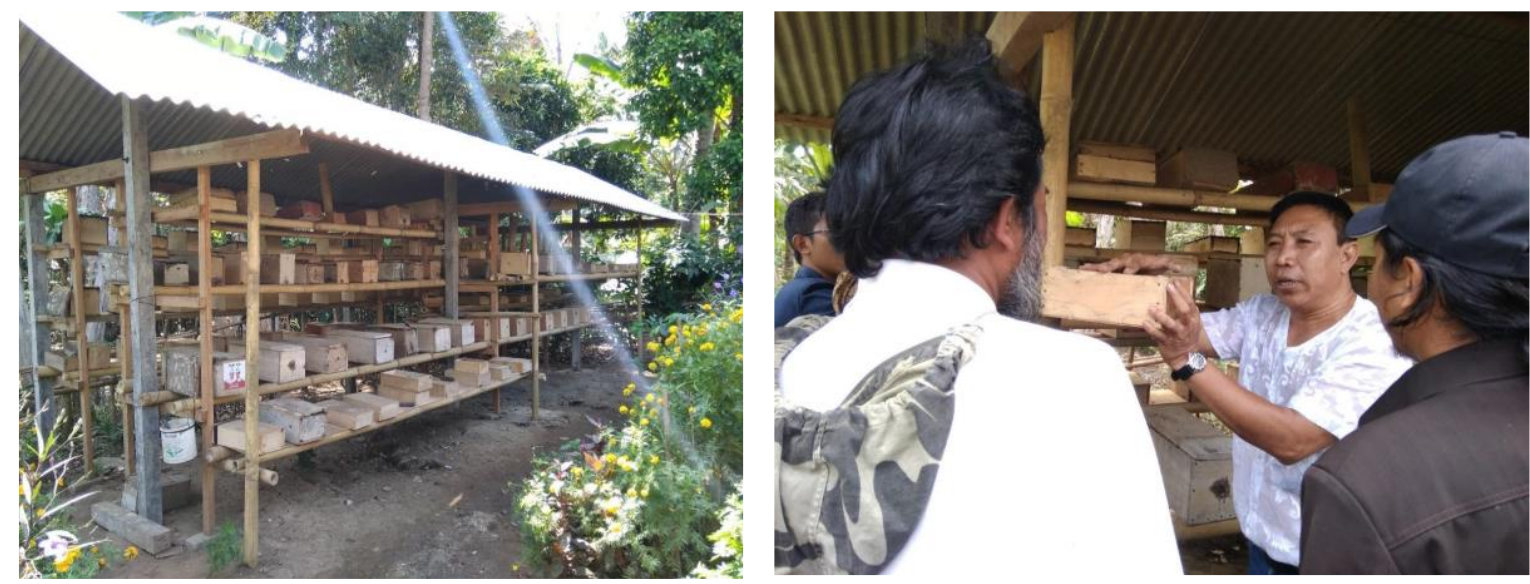

Gambar 2. Rumah stup dan simulasi pemidahan koloni.

Selanjutnya dilakukan pendampingan pada simulasi pemindahan koloni lebah (ratu) baik dari alam ke dalam stup atau dari satu stup ke stup lainnya. Proses ini merupakan hal yang paling penting untuk diperhatikan dan dilakukan secara hati-hati pada malam hari setelah semua koloni kembali ke sarang atau dinihari ketika koloni belum mencari pakan. Secara teknik, pemindahan koloni lebih mudah dengan cara memindahkan ratunya terlebih dahulu dan berikutnya secara otomatis anggota koloni akan mengikuti ratu berpindah tempat (Surata, 2017). Setelah semua koloni berpindah, stup yang baru didiamkan dan dikondisikan selama 2- 4 minggu agar koloni dapat beradaptasi dengan lingkungan yang baru (Gambar 2). Pada simulasi pemindahan koloni lebah hanya sekitar 5 orang petani atau 20\% dari total anggota kelompok yang dapat dan mampu melakukan pemindahan koloni dengan baik dan betul. Menurut Baiquni (1999) bahwa inovasi yang diberikan tidak semestinya dapat dilakukan oleh seluruh anggota mitra sasaran, namun melalui beberapa anggota mitra yang potensial dan berbakat diyakini inovasi tersebut nantinya akan berkembang dan akhirnya digunakan oleh seluruh anggota kelompok.

Kegiatan berikutnya adalah kegiatan studi banding kelompok mitra sasaran kepada Kelompok Peternak Lebah Trigona "Usada" milik Bapak Yudi Wartono di Desa Delod Berawah, Kecamatan Mendoyo, Kabupaten Jembrana untuk menambah pengalaman dan melihat usaha peternakan lebah trigona yang lebih maju (Gambar 3). Dalam kegiatan studi banding ini peserta diajak melihat cara atau teknik penempatan stup, , cara perawatan stup, teknik panen madu yang higienis dan cara perawatan tanaman sumber pakan lebah Trigona spp. Pada kesempatan ini juga dilakukan diskusi tentang teknik budidaya lebah Trigona, teknik prosesing panen madu yang baik dan pemasaran produk madu dengan nara sumber Bapak Yudi Wartono. Seluruh peserta merasa memperoleh pengetahuan tentang cara budidaya lebah, kondisi alam yang disukai lebah, perawatan koloni lebah, cara pemanenan serta cara memproduksi madu yang higienis,mengenal stup yang modern, mendapatkan pengalaman langsung. Kesemuanya itu sangat bermanfaat terutama dalam pengembangan ternak lebah, karena dengan berkembangnya ternak lebah maka produktivitas madunya akan meningkat juga dan secara otomatis akan meningkatkan pendapatan kelompok lebah madu khususnya dan masyarakat desa Antapan pada umumnya .

Pada akhirnya Kepala Desa Antapan beserta jajarannya serta kelompok mitra sasaran merasa sangat senang dan merespon positip serta bertekad untuk mengembangkan lebah trigona dengan 
harapan nantinya disamping dapat meningkatkan pendapatan kelompok lebah madu khususnya maupun masyarakat desa Antapan umumnya, disamping itu juga sebagai atraksi wisata yang dapat menunjang pengembangan Desa Wisata di Desa Antapan, Kecamatan Baturiti, Kabupaten Tabanan

\section{SIMPULAN DAN SARAN}

Kegiatan pemberdayaan masyarakat melalui program KKN-PPM di Desa Antapan, Kecamatan Baturiti, Kabupaten Tabanan berupa pengembangan budidaya lebah trigona dapat berlangsung dengan baik yang ditunjukkan dengan adanya partisipasi aktif dari kelompok sasaran serta ipteks yang ditawarkan dapat diterima oleh kelompok sasaran. Partisipasi aktif kelompok mitra sasaran pada seluruh tahapan kegiatan dikatagorikan cukup baik yaitu berkisar $75-100 \%$ atau secara ratarata sebesar $87,5 \%$.

\section{UCAPAN TERIMA KASIH}

Penulis mengucapkan terimakasih yang sebesar-besarnya kepada Direktorat Riset dan Pengabdian Masyarakat Kemenristek Dikti atas dana yang telah diberikan sehingga kegiatan ini dapat dilaksanakan. Terimakasih pula penulis sampaikan kepada Ketua Lembaga Pengabdian kepada Masyarakat, Tim KKN PPM, Kepala Desa Antapan, para Kepala Dusun dan Kelompok Lebah Madu Manggar Sari serta mahasiswa KKN PPM yang telah membantu kelancaran kegiatan ini sehingga kegiatan dapat terlaksana sesuai harapan.

\section{DAFTAR PUSTAKA}

Baiquni, M. 1999. Metode dan Teknik Partisipasi dalam Pengembangan Perdesaan. Jogjakarta: UGM-Press. Chambers, R. 1987 Pembangunan Desa Mulai dari Belakang. (Pepep Sudradjat, penerjemah). Jakarta : LP3ES.

Sihombing, D.T.H.2005. Ilmu Ternak Lebah Madu. Gadjah Mada University Press.

Surata, I.K. 2017. Budidaya Lebah Madu Kele-Kele (Trigona spp.). Buku saku /Buku Pedoman 